


\section{Reseñas de exposiciones}

Manuel Munive Maco

Investigador independiente rupestrecontemporaneo@gmail.com

\section{LOS TRINOS}

\section{Rubén Mamani. Instituto Cultural Peruano Norteamericano de Puno}

Rubén Mamani lo ha conseguido: en las xilografías que componen la serie titulada Los Trinos percibimos que los músicos tocan y que los asistentes al concierto bailan con fruición al ritmo de esa música. Si en una primera mirada descubrimos los instrumentos eléctricos, muy pronto, al reconocer los timbales, reparamos en que la música ejecutada no es precisamente el rock. Finalmente, las versiones a color de estas estampas -en fucsias, anaranjados y verdes- nos orientan al recordarnos que es mediante esos rutilantes colores que los conciertos de la cumbia andina se anuncian en el espacio urbano. Y cuando reparamos en que el propio grabador es bajista de un conjunto de música chicha, todo encaja. Si hasta hace poco los grabados que mostraba en exhibiciones individuales y colectivas representaban paisajes, ritos y personajes altiplánicos, elementos de un universo aimara que ha hecho suyo mediante su vínculo matrimonial y su residencia de muchos años frente al lago Titicaca, hoy nos convoca para que, apelando una vez más a sus vivencias personales, conozcamos su visión de la experiencia musical "chichera" desde la autoridad que le confiere ser uno de sus instrumentistas.

La serie plantea una secuencia, una suerte de relato que empieza con aquella estampa en la que varios varones cabizbajos, seguidos por sus alargadas sombras, se dirigen al recinto del concierto del cual emana una luz sobrenatural. Esta pieza es notable porque contiene la promesa de la fiesta y su poder redentor en medio de la noche. Una vez adentro, Mamani comparte con nosotros sus diversos puntos de vista del espectáculo, ubicándonos lejos o al pie del escenario, entre los que bailan con los ojos cerrados -porque la música es invisible- o en medio de los músicos que parecen bailar también con sus alargadas guitarras, articulando mediante estas "instantáneas” una visión completa del concierto. 
Rubén Mamani nació en Arequipa en 1961, donde también se formó como pintor y grabador en la Escuela de Bellas Artes Carlos Baca Flor y en la Escuela Profesional de Artes de la Universidad Nacional de San Agustín. Se especializó en grabado en el taller de Luis Solorio. Actualmente es docente en el Taller de Grabado de la Escuela de Arte de la Universidad Nacional del Altiplano en Puno, ciudad en la que vive y trabaja. Ha realizado seis exposiciones individuales hasta la actualidad; la más reciente, Los Trinos, en la galería del Centro Cultural Peruano Norteamericano de la ciudad de Puno, una colección de xilografías que constituye el más logrado homenaje gráfico a la "chicha", el género musical que acompañó a una migración que llegó para quedarse y que modificó para siempre el rostro de las grandes urbes del Perú.

\section{GEOMETRÍA SENSIBLE \\ Carlos González. Enlace Arte Contemporáneo}

A medida que conozco el proceso artístico de Carlos González (Lima, 1936) le atribuyo más importancia a la insólita decisión que tomó aquel día de 1957, cuando, gracias a su siempre aguzada intuición, decide no matricularse en la Escuela Nacional de Bellas Artes y elige entrenarse como artista gráfico en la agencia publicitaria más importante de Lima. ¿El joven artista era consciente de que al hacerlo estaba eligiendo el camino formativo más largo, solitario e incierto, así como el más libre, experimental y aventurado? Total, si había aprendido a dibujar por su

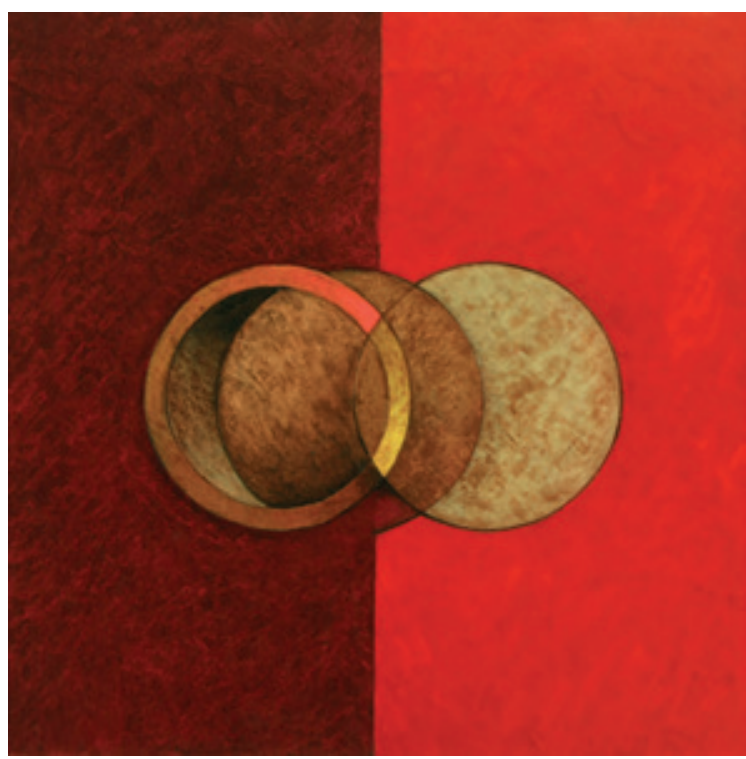
cuenta e incluso llegó a preparar sus propios óleos según las recetas de Leonardo en su casa de La Punta, era probable que el secreto para convertirse en artista radicara, fundamentalmente, en trabajar incesantemente aunque fuese en soledad.

Y esa elección, determinó que el suyo fuera uno de los periplos creativos más singulares, fructíferos e independientes de la historia del arte peruano de la segunda mitad del siglo $X X$, el cual, partiendo de las experimentación gráfica, se desborda o se expande hacia el campo de las indagaciones plásticas geométricas circunscritas al plano para, incorporando la tridimensionalidad, arribar a instancias cabalmente escultóricas e incluso monumentales.

Geometría sensible es el título de esta notable serie de pinturas y constituye el capítulo más reciente de la larga trayectoria creativa que inició su autor a principios de la década de los sesenta, cuando participó en los Salones de Arte Gráfico Aplicado presentados en el Instituto de Arte Contemporáneo en 1961 y 1963, pero particularmente a partir de 1967, cuando inaugura bajo el título de Cinetismo su primera muestra personal como artista plástico en la galería Quartier Latin, exhibición a la que seguiría una veintena de individuales, configurando un proceso creativo cuyo atento estudio puede resultar ejemplar para cualquier artista joven de hoy. 
Ya en 1998 nuestro artista pronuncia la frase "geometría sensible" para sintetizar su obra, específicamente cuando la contempla reunida en la muestra antológica inaugurada entonces en la Galería de Artes Visuales de la Universidad Ricardo Palma bajo la curaduría de Alfonso Castrillón.

He tenido tendencias hacia la "geometría sensible" [...]. Ya no utilizo la línea dura. Si bien existe todavía una conceptualización [...] que tiene que ver con la estructuración del cuadro y las formas geométricas, también hay una dosis de lo gestual, un poco de libertad. No se trata del compás riguroso, sino que al lado de ello existe una mancha puesta ahí deliberadamente [...]. Existe un retorno de alguna manera, una vuelta a los inicios, pero siempre en busca de renovación, con algún componente nuevo. ${ }^{1}$

En efecto, su trabajo plástico se erige sobre el lenguaje de las formas geométricas, pero sobre la base de una valoración estética que se impone al racionalismo que había primado en sus tempranas incursiones en el estricto campo del "cinetismo", corriente cuyo nombre usó una vez más para titular su segunda muestra personal, inaugurada en 1968, esta vez en el Instituto de Arte Contemporáneo (IAC).

En aquellos tiempos su propuesta pictórica de naturaleza eminentemente geométrica abrevaba de las experimentaciones gráficas que su oficio de diseñador le demandaba cotidianamente, constituyendo una suerte de "laboratorio" que le permitió abordar el fenómeno plástico sin los parámetros habituales de composición académicos.

Por otro lado, la consagración del arte cinético en la tercera Documenta de Kassel (1964) y su gran divulgación a partir de la muestra El ojo sensible, inaugurada en el MoMA al año siguiente, acontecimientos de los que González estaba al tanto por las reseñas en las revistas y anuarios que circulaban en las agencias de publicidad y diseño muchísimo antes que en los libros de arte, afianzaron su elección por la abstracción "geométrica sensible" que lo definen hasta hoy, caracterizado por un tratamiento cromático preciso, una manera de hacer que se consuma cuando burila "mates" en la década de los setenta, es decir, cuando "graba” sobre orgánicas superficies esféricas que lo conectan directamente con la plástica precolonial y tradicional peruanas.

La prolífica y compleja obra artística de González -sin contar su también cuantiosa y notable producción en el ámbito gráfico- fue posible gracias a la capacidad de dividir perfectamente en dos su tiempo y su mente: el quehacer en la agencia publicitaria o el estudio de diseño no solo no interfería con el espacio de creación plástica habilitado en su casa. sino que lo nutría y lo complementaba: si en la oficina desplegaba sus destrezas en el arte figurativo al momento de definir, por ejemplo, la portada de una novela, en su casa/ taller, por el contrario, se sumergía en el lenguaje abstracto geométrico. Solo un equilibrio semejante explica la cronología de sus muestras personales, inauguradas generalmente a intervalos de dos años, las cuales revelaban siempre cambios palpables o sutiles, tanto en el aspecto conceptual y formal, o saltos más rotundos como el que se produjo en su individual de 1995 en la Galería Trapecio, a partir de la cual se consolida como escultor y obtiene distinciones como tal.

Sí considero un acierto el que Carlos González se formara "indirectamente" como artista plástico en el ejercicio cotidiano del diseño gráfico, no es solo por lo novedosa que podía resultar esa operación conceptual, sino por la infinidad de recursos técnicos con los que un artista gráfico de esos tiempos contaba para realizar sus logotipos, isotipos, carátulas, afiches y otras piezas. En las conversaciones sostenidas con el artista me quedó claro cómo, a

1 González, C." La geometría sensible”. En Diario Cambio. 24 de octubre de 1998 (entrevista de César Pita Dueñas). 
diferencia de un pintor que puede trabajar exclusivamente con óleos o acrílicos de por vida, él y sus colegas disponían de tintas, pigmentos y emulsiones; recurrían a la xerografía, a la fotografía, a la serigrafía, al fotomontaje y al collage, sin mencionar el arsenal de lápices, pinceles, plumas, tiralíneas y cuchillas; y por último, con el amplio margen de experimentación que otorgaba la supervisión del trabajo en el corazón de una imprenta. En esta experiencia tangible en el uso de materiales e instrumentos radica, me parece, la calidad de la impronta de González al plasmarse sobre el papel, la tela, la madera, el bronce o la piedra.

Y esa pericia en el trabajo de las superficies es ostensible en esta colección de cuadros recientes, en los que el círculo es el protagonista del espacio pictórico, ya sea en solitario, centralizado, o desdoblado y multiplicado siguiendo un eje horizontal que nos lleva a verlos como cuerpos celestes en traslación. El cuadrado aparece también, pero supeditado o imbricado por la dinámica de las circunferencias. Predominan dentro del conjunto aquellas piezas resueltas en gama de ocres, evocando la terrosidad alfarera, y por qué no, la superficie tostada de los mates que hace poco más de cuarenta años nuestro artista burilara con trazos abstractos semejantes a las incisiones o surcos que hoy demarcan con sutileza la líneas circulares, todo un descubrimiento de este artista racional y sensitivo.

\section{VIVIR}

\section{Nereida Apaza. El Cultural de Arequipa}

Un aula escolar, "un rincón hogareño" y una casita de tela a la que podíamos entrar caminando, fueron las tres instalaciones que conformaron Vivir, la más reciente muestra individual de Nereida Apaza, signadas todas por la austeridad monacal de las bóvedas de sillar que las albergaban en las nuevas salas conexas de El Cultural de Arequipa.

Conviene ahora insistir en la des-

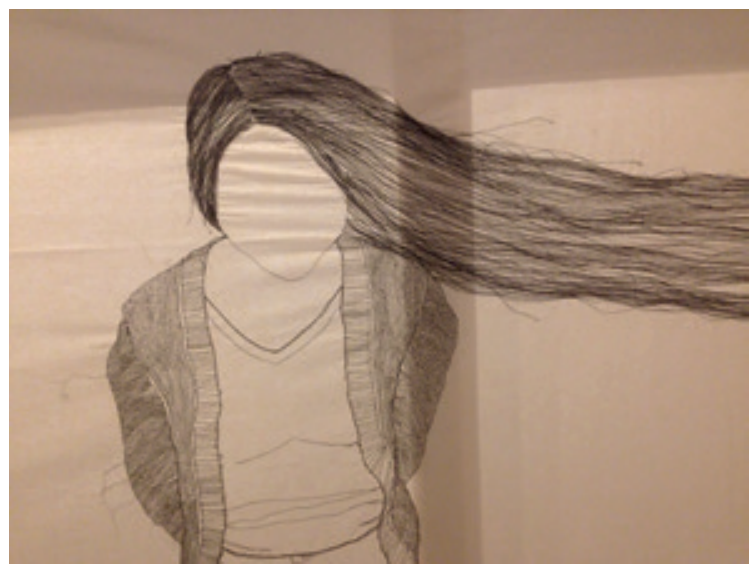
cripción de cada una de estas "puestas en escena”, aparentemente diáfanas, para que comprendamos que algo más críptico y profundo resultaba de su articulación y declarar, desde ya, que este escrito no es más que la aproximación a una poética en pleno desarrollo: tanto el aula escolar -con el marco flotante de un pizarrón, cuatro carpetas dobles con ocho cuadernos y un mapa del Perú-, como aquel rincón doméstico con un librero y una mesa con su silla situados en la esquina opuesta, compartían la sala de planta rectangular por la que el público accedía a la exhibición. Y en el centro de la segunda sala, de tal manera que la podíamos rodear, estaba la casita confeccionada completamente en tela, con su techo de doble vertiente y una puerta a través de la cual descubríamos unos "muros" y un cielorraso con símbolos y textos bordados como el contorno de una muchacha sin rostro, casi a escala, cuya larga cabellera de hilos negros ondeaba - como el tiempo - un par de metros. (¿Un autorretrato velado de la autora o el de su madre o el de otra mujer de su genealogía, cuando joven? Todo es probable). La luz que ingresaba a través de la ventana del recinto le confería a esa visión arquetípica de la "casa” una cualidad litúrgica.

El aula, o más precisamente, la carpeta y el pizarrón, como humilde e improductiva -o subestimada- utilería de la "Educación nacional", han sido abordados anteriormente por 
la artista: por ejemplo, en una muestra personal colaborativa de hace unos años en el Centro Cultural de la Universidad de San Agustín y, en una versión sintética -una sola mesa y una silla con algunos cuadernos- que resultó Finalista en la primera edición del certamen de arte contemporáneo que organizó, en su sala del centro de Lima, el Instituto Peruano Norteamericano. (Incluso un concepto semejante anima el cuadro que Nereida donó al Museo de Arte de la Universidad Nacional Mayor de San Marcos hacia 2015, sobre el cual había bordado, cartesianamente, decenas de diminutos uniformes escolares femeninos, sugiriendo al aula como un camposanto y a la "Educación" como un horizonte de adocenamiento, grisura y caducidad).

Si bien el aula, el rincón doméstico y la casa parecen integrados en Vivir por constituir hábitats del crecimiento físico y psíquico de una persona, lo que cohesiona la propuesta actual de Nereida Apaza es, en verdad, el procedimiento técnico con el que la define o la complementa: el paciente bordado a mano con el cual no sólo dibuja formas y añade color sobre grandes bastidores y "cuadernos" y "casas" de tela, por ejemplo, sino que le ha permitido integrar la escritura poética que involucra al espectador también con una experiencia de lectura que, en lugar de "esclarecer" lo que ve, lo sumerge en una metaforización mayor. (Esto se hace particularmente evidente en la "leyenda" del mapa del Perú bordado, la cual revela una cartografía personal -y emocional- del territorio patrio).

Nereida Apaza conoce lo que valen las palabras y creo que esa frecuentación, la condujo a traspasar las fronteras disciplinarias convencionales. Y mediante su "apropiación" del bordado, para plasmar su obra visual, se ha conectado con la tradición textil del Perú, vinculando los milenarios tejidos Nasca con especímenes tan modernos y populares como la arpillería, por ejemplo. Es por esta habilitación artística del bordado como instrumento de creación contemporánea, que Nereida se encuentra actualmente en Londres, realizando una Residencia por invitación del Museo Británico: allí le han propuesto el reto de trabajar a partir de una inmersión, en sus depósitos de textilería precolombina peruana, es decir, después del encuentro directo con el arte de sus mayores.

\section{ESTAMPAS TRUJILLANAS}

Mariano Alcántara La Torre. Casa de la Identidad Regional, Trujillo

Las primeras noticias del trabajo xilográfico de Mariano Alcántara La Torre (1908-2000) las encontramos en el libro Grabadores en el Perú que el desaparecido investigador José Fernández publicó en 1995. En ese volumen, el arte de Alcántara está representado por ocho estampas en las cuales, desde sus títulos, se transparenta su identidad trujillana: Pórtico y balcón colonial, Retrato de José Eulogio Garrido, Matinal mochero, por ejemplo, así lo demuestran. De allí la elección del título de esta primera muestra antológica de sus grabados.

Por eso conviene que empecemos agradeciendo al señor "Pepe" Fernández -también trujillano- por haber sembrado la inquietud

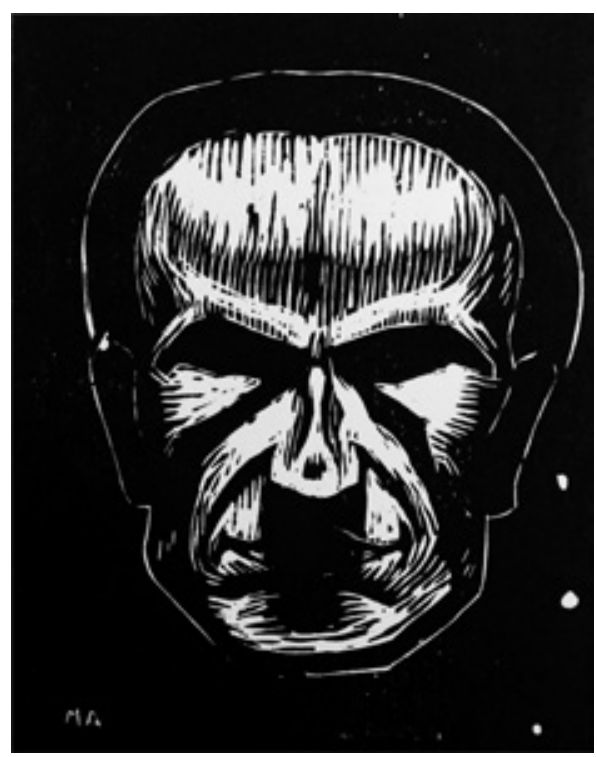
por indagar acerca de este grabador conocido 
sólo por un muy reducido círculo de intelectuales liberteños. Debemos agradecer también a sus hijos, quienes preservan diligentemente una treintena de sus tacos originales, gracias a los cuales se pudo preparar esta muestra y la que se inauguró posteriormente dentro del marco de la Primera Bienal de Grabado de Arequipa. Con estas dos exhibiciones el trabajo de Alcántara ingresa definitivamente en la historia del grabado peruano.

El caso de Mariano Alcántara es singular pues antes que grabador fue un pintor autodidacta que logró hacerse de un oficio notable patente en los retratos al óleo, donde se reconocen; rigurosidad y autoexigencia que podían explicarse, tal vez, por ser hijo de José Alcántara La Torre, uno de los más exquisitos ilustradores de la revista limeña Variedades, de quien adopta el segundo apellido al momento de firmar cuadros y artículos.

Pero Mariano fue también, y paralelamente, un librero de vocación, es decir, alguien que no solo facilita el encuentro del libro y su lector sino que además convierte su establecimiento en un recinto hospitalario para la lectura y la tertulia intelectual. Cristóbal Campana recuerda que los miembros del grupo Trilce se adueñaban de la librería Divulgación durante sus cónclaves literarios y que, aunque "espantaban" a la clientela potencial, don Mariano jamás se molestó y que, por el contrario, disfrutaba de albergar a toda esa juventud ilustrada que podía consultar sus estanterías sin reparos.

¿Pero qué lo llevó a incursionar en la xilografía? En verdad, muy pocos pintores sienten tanta afinidad por el grabado (uno de esos raros casos fue Julio Camino Sánchez, por ejemplo). Tal vez su bibliofilia explique esa predilección si consideramos que la imprenta y el grabado en madera están estrechamente vinculados en la ya longeva historia del libro. Sabemos también que algunas publicaciones periódicas regionales estuvieron ilustradas por las estampas de nuestro artista. Las pequeñas dimensiones de sus matrices, que las habilitaban para insertarse en una página con textos, afianzan la intuición de que fueron concebidas como viñetas. Lo cierto es que fue un grabador solitario y como tal llegó a forjarse una técnica eficiente, como lo corroboran sus “cabezas" de Vallejo, el atardecer en Huanchaco o la fachada de la Casa Ganoza Chopitea, entre otras estampas.

No sabemos cuántos tacos grabó Mariano Alcántara y ese inventario queda pendiente. Afortunadamente, el conjunto que preservan sus herederos nos permite conocer su personalidad, tanto su amor filial como su valoración del paisaje natural, cultural y urbano de La Libertad, así como su fe religiosa, su filiación política y sus preferencias literarias y librescas.

Esta exposición, además, constituyó el aporte histórico del Encuentro Internacional de Grabado, Trujillo 2019. Agradezco a Gerardo Salazar quien, a inicios de marzo de este año compartió conmigo este hallazgo y me invitó a participar de ese proyecto con una ponencia, lo que me permitió, además de inspeccionar los tacos originales, asistir a la exposición de las impresiones xilográficas realizadas especialmente.

\section{LA CELEBRACIÓN DE LAS CENIZAS José Luis Carranza. Enlace Arte Contemporáneo}

Resulta cada vez más difícil distinguir lo que pasa en cada escena: los personajes, aunque imbricados entre sí, además de evidenciar que experimentan visiones ocasionadas por trastornos y tormentos

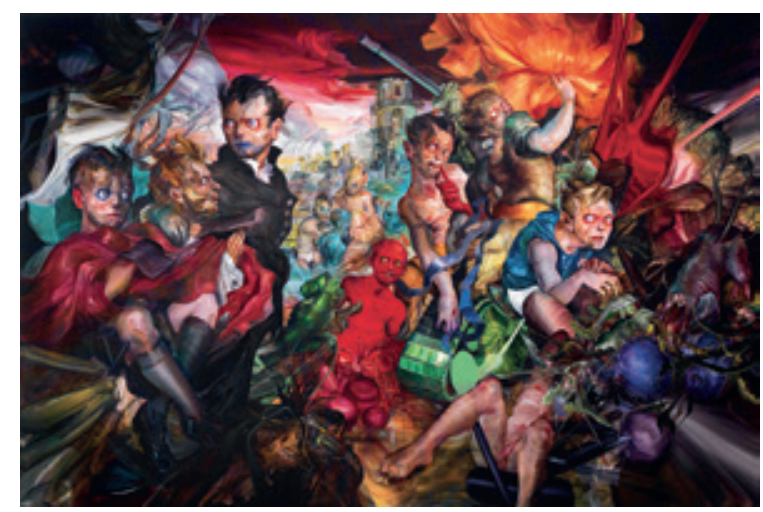


distintos, llevan atuendos que indican que proceden también de diferentes épocas: individuos de talante bíblico, centuriones, naturalistas del XIX así como verdugos modernos y sus pueriles víctimas, aparecen confinados en ese cenagal lujuriante que constituye la locación primordial del imaginario pictórico de José Luis Carranza (Lima, 1981).

¿Y quiénes son ellos? Podemos identificarlos con certeza, sólo cuando el pintor los nombra en el título de la obra y los consigna en un rótulo o en sus catálogos. Porque ni un erudito en textos sagrados o antiguos podría hacerlo por sus atributos o acciones, pues nuestro artista no se ciñe al canon iconográfico y lo usa libremente y sin escrúpulos. Por ejemplo, ¿nos hallamos en capacidad de precisar cuál de los cuatro sujetos pasmados del tondo titulado Lázaro nacido, es el resurrecto? Se trata de uno de los personajes más célebres del Evangelio de San Juan y con el cual todos, creyentes o no, estamos familiarizados, pero aun así no podemos estar seguros. Y esto es más arduo con personajes como Artemisia, quien, según Herodoto, fue una brillante líder militar, la cual, en la pintura homónima de Carranza se ve sentada sobre una bomba aérea semejante a la que alguien transporta en hombros en La victoria sobre el sol; o como en Agár en el desierto, en alusión a la concubina de Abraham, otro personaje recóndito del Antiguo Testamento, aquel libro dominado por un dios que sabe odiar y pone a prueba con sadismo la fe de sus hijos, como nos lo recuerda la escena central del cuadro Golconda, que no es otra que la versión modernizada del sacrificio de Isaac. Y precisamente con ese libro milenario, colmado de pasajes punitivos, el joven pintor peruano parece regodearse.

Porque sí hay un mensaje latente en estos cuadros de formatos crecientes y cada vez más intrincadas alegorías, aspectos que delatan su pulsión muralista y totalizadora, es que la Naturaleza terminará por imponerse y devorará todo aquello producido por el hombre y su Cultura. En cuanto a esto, la clarividencia del artista es indubitable: el Apocalipsis consistirá en un exclusivo ajuste de cuentas con la Humanidad; catástrofe después de la cual animales y plantas prosperarán sin los perjuicios que les ha ocasionado ese bípedo implume, el último sujeto de la Creación y el más soberbio, ciego y frágil al estar recubierto, desgraciadamente, por una piel a la que casi todo lastima y hace sangrar.

En aproximaciones anteriores dijimos que la pintura de José Luis Carranza se fundamenta, como pocas, en una acuciosa revisión de la pintura europea, cuyos especímenes más notables ha escudriñado en sus museos desde 2010, año en el que viaja por primera vez a París gracias a la beca de la Embajada de Francia. Por eso percibimos que estamos ante una pintura que se sabe parte de una tradición a la que, simultáneamente, pretende liquidar con sus visiones del fin del mundo.

En las piezas que componen la exhibición La Celebración de las Cenizas -título, en verdad, de la obra más grande- se transparentan, sobre todo, las deudas del pintor con elementos y recursos característicos del manierismo: el contraposto de sus personajes llevado al máximo $\mathrm{y}$, en especial, esas manos de dedos expresivos, casi pequeños cuerpos con vida propia. (Incluso el blanco relampagueante en el faldón de Artemisia nos recuerda el modo en que el Greco dotaba de brillo a las vestiduras de sus santos). Pero ¿por qué Carranza privilegia el manierismo sobre otra etapa de la historia del arte? Porque la artificiosidad anatómica propia de la pintura manierista puede, con un poco de perversidad, evolucionar de una dislocación a una mutación, como la que padece el personaje que acompaña a Agár, cuyos brazos semejan las tenazas de una mantis religiosa. Mutaciones que se extreman en los brazos con la consistencia de filamentos de piel de uno de los sujetos de Lázaro nacido, o en el torso saeteado e informe del protagonista de La llegada de los ejércitos.

Cada pintor -cada artista- debe ser capaz de erigir un mundo inconfundible y, a la vez, dominar el material con el que desarrolla su oficio. Durante esta última década de trabajo sostenido, Carranza ha llevado muy lejos su pacto de complicidad con el óleo de modo 
que, cubriente o translúcido, rutilante u opaco, aplicado con precisión milimétrica o gestualmente expandido, ha conseguido dotarlo de una cualidad orgánica perturbadora.

Para José Luis Carranza la carne es sustancia oleosa y la sangre pintura coagulada.

\section{COSECHANDO ESTRELLAS \\ Luis Solorio. Alianza Francesa de Arequipa}

El amor como una ceremonia de dos que se entienden sin palabras. El amor como un brindis, como una música secreta y como un baile. El amor como un juego de niños que desconocen el pudor de andar desnudos. El amor como un abrazo y como un "vuelo". El amor como la entrega dichosa de dos que celebran el azar que los juntó. Y casi siempre -evidente o intuido- un paisaje natural de fondo, ya sea un huerto, el campo, la jungla o -por qué no- cierto volcán tutelar. Estas son algunas de las imágenes que el público reconocerá en las numerosas estampas que integran Cosechando estrellas, la reciente muestra individual de xilografías de Luis Solorio con la que la Primera Bienal de Grabado de Arequipa inauguró su programa de exposiciones.

Para desarrollar esta nutrida serie inédita -constituida por cerca de cincuenta piezasSolorio tuvo que alejarse momentáneamente de la temática neoindigenista que ha caracterizado su obra, tanto en grabado como en pintura, durante los últimos 25 años, la cual se desarrolla preferentemente en medio de paisajes andinos que sirven de escenario para grupos de personajes que parecen existir coreográficamente. Campesinos, pastores, músicos y danzantes, vistos siempre desde lejos y generalmente en la cima de una montaña, integran el "elenco" predilecto del artista y, mediante ellos, ha recreado, idealizándolas, un sinnúmero de instantáneas de su infancia en Puno y Cusco. Porque si algo define la poética de este artista es el hecho de abrevar en su memoria más temprana para componer las escenas plasmadas en sus estampas y cuadros.

Luis Solorio nació en el distrito cusqueño de Sicuani en 1955 y pasó gran parte de su infancia y adolescencia en Juliaca (Puno). En Lima asistió al Taller de Dibujo de Cristina Gálvez y se formó como pintor y grabador en la Facultad de Artes Plásticas de la Universidad Católica del Perú. Se especializó en grabado en la École Superieure d'Arts Visuels de Ginebra, Suiza, y en el Taller Bigako de Tokio (Japón), donde investigó sobre la tradición del ukiyo-e. Asimismo realizó estudios en el Basler Papiermühle de Basilea (Suiza). Expone individualmente desde 1982 en el Perú y en el extranjero. En 2012 realizó una muestra antológica de su obra pictórica y gráfica en el Museo de Arte Contemporáneo de Arequipa y a inicios de 2019 presentó una muestra individual de grabado en España. Fundó en Arequipa el taller Lluvia de Sol, que funcionó durante la primera década del presente siglo. Vive y trabaja en Arequipa.

En Cosechando estrellas, Solorio incursiona en una temática sumamente distante de la que acabamos de describir, pues lejos de conformar grupos que existen al aire libre, sus 
protagonistas forman una pareja juvenil a cuya intimidad, como voyerista, el espectador tiene total acceso. Equilibradamente eróticos y lúdicos, estos grabados articulan una suerte de celebración de la pareja y del universo privado que en ella se instaura gracias al amor. Siguiendo esta idea podemos desentrañar el enigma del título: ¿es posible recolectar estrellas de la tierra como si fueran frutos? ¿Solorio propone el hallazgo del amor como recompensa o como un merecimiento? Creemos que sí.

\section{REPASO}

José Lara. Galería del Monasterio de Santa Catalina, Arequipa

En las xilografías emblemáticas de esta serie titulada Repaso, reconocemos, prioritariamente, a algunos niños varones que se entretienen a solas y con una seriedad que parece prefigurar al adulto en el que se convertirán en el futuro. Mediante estas imágenes, en las que aparece estrictamente un único jovencito por estampa, José Lara -quien es padre además de artistatrata de reconstruir la biografía del niño solitario que fue él mismo -acaso también sensible y perplejo ante el lugar que ocupaba en el mundo-, observando en silencio y con total dis-

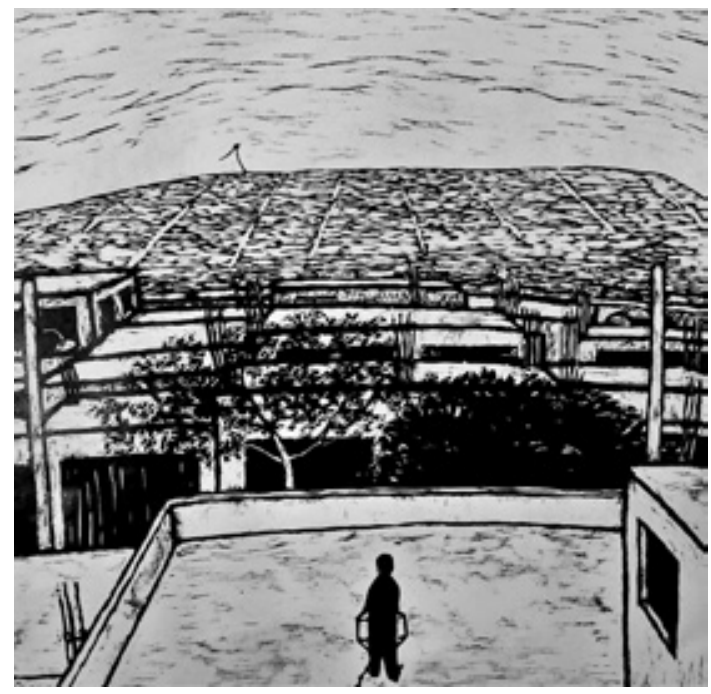
creción a los pequeños que hoy lo han relevado en los rincones de la ciudad que colonizó en su infancia. Y al llevarlos al grabado invita al espectador a hacer una operación mental semejante, un "repaso" sobre aquella etapa vital proclive a la alegría, pero no exenta de gravedad y de ensimismamiento.

Lara, posiblemente para facilitar nuestra empatía con sus imágenes y de paso para que activemos nuestra memoria y nos pongamos en su lugar, oculta hasta donde es posible la fisonomía de sus niños, presentándolos de espaldas, absortos en lo que hacen o distantes y en medio de una urbe que empiezan a descubrir y a hacer suya mientras juegan.

Dos de estas imágenes se expusieron en Lima en el verano de 2018 dentro de una muestra colectiva de grabado cuya curaduría estuvo a nuestro cargo, lo que nos deja colegir que, desde hace por lo menos tres años, José Lara indaga sobre este tema inédito en la historia del grabado peruano -tratado larga y exclusivamente en pintura por Aquiles Ralli- el cual resulta opuesto y complementario al que lo caracterizaba y que tan bien resumido estuvo en Ciudad de Lara, la exposición antológica presentada en 2014 en el desaparecido Museo de Arte Contemporáneo de Arequipa. Me refiero a aquellas vistas urbanas en las que figuraban los elementos que definen la singular arquitectura de Arequipa, es decir, sus fachadas y claustros de templos virreinales, mansiones, plazas, puentes, callejuelas antiguas y también, desde luego, las edificaciones nuevas y emergentes. Si en aquel paisaje urbano la presencia humana no existe y resulta evocada mediante la elocuencia de los espacios arquitectónicos, en Repaso, más bien, son estos pequeños personajes a través de sus retratos "elusivos" los únicos protagonistas de la ciudad.

José Lara Quilla nació en Arequipa en 1968. Se formó como pintor y grabador en la Escuela Profesional de Artes de la Universidad Nacional de San Agustín de su ciudad natal, donde 
se desempeña como docente desde el 2001. Ha obtenido dos veces el Tercer Premio en el Concurso Nacional de Pintura Michell y Cia., en sus ediciones de 1988 y 1993. Ha realizado cinco exposiciones individuales además de la muestra antológica que ya mencionamos, en la que reunió su obra gráfica ejecutada desde 1997. Vive y trabaja en Arequipa.

\section{CORTAR EL AIRE}

\section{Tania Bedriñana. Museo de} Arte de la Universidad Nacional Mayor de San Marcos

¿Qué es, después de todo, una sala de exposiciones? ¿Un recinto no habitado, ex profesamente liberado de funciones utilitarias y administrativas, dispuesto a albergar temporalmente, y de vez en cuando, lo extraordinario?

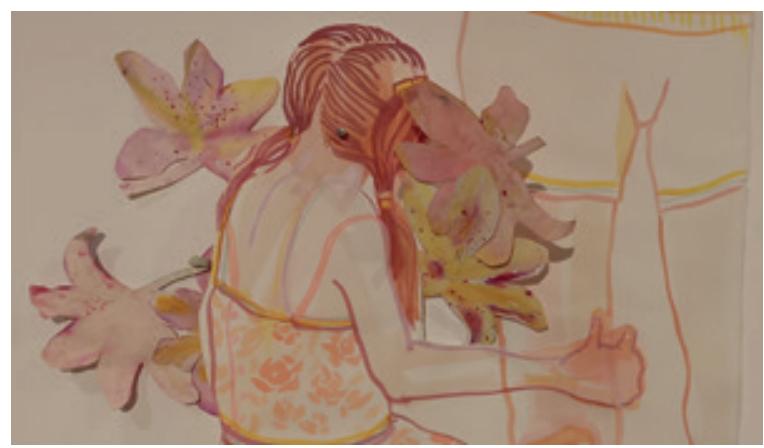
¿Una habitación tal vez inconscientemente reservada para auxiliarnos, propiciando escapes momentáneos de la grisura cotidiana, y en la que se puede, todavía, experimentar aquello que sólo puede producirse en solitario aislamiento y silencio de sus cuatro paredes? ¿Un lugar de retiro, de introspección?

Los espacios expositivos parecen recobrar su importancia cuando acogen participaciones notables como ésta de Tania Bedriñana, en la que el espectador experimentará, seguramente, un inicial desconcierto: ¿Estamos ante una reconstrucción del taller berlinés de la artista? ¿El montaje que vemos podría seguir variando infinitamente o existe un secreto orden articulándolo todo? O una interrogante más grave aún: ¿La artista nos está invitando a entrar en su cabeza, al epicentro de sus visiones? ¿Hasta ese punto esta muestra es una "entrega"?

Personalmente esta gran instalación -o esta antología de instalaciones- pues encontramos aquí recortes -cut out-realizados desde 2005, cuando la artista inicia su experimentación con el papel cortado y calado, me lleva a pensar, por un lado, en la plástica rupestre, en esas expresiones arcaicas pintadas o grabadas en cavernas y abrigos rocosos, -fundamentalmente contornos- que no pueden concebirse desligadas de la urgencia ritual que las originó y, a la vez, el hecho de que esto se produzca dentro de una vetusta casa colonial del centro histórico de Lima -aunque haya sido restaurada- me lleva a asociar los recortes de Tania, que consisten básicamente en representaciones femeninas particularmente pueriles, con los vestigios de una pintura mural antigua recientemente descubierta y preservada.

Tal vez todo lo dicho explique el halo de silencio que impone el conjunto erigido en este espacio. Y también a la aleatoriedad connatural del recurso técnico que, en este caso, materializa siluetas humanas recortadas sobre papeles o lienzos previamente pintados o impregnados de una coloración orgánica que las convierte en fracciones de cuerpos lacerados -cabezas, torsos, piernas-, especialmente aquellos hechos a escala natural. Y aquí es donde nos asalta el presente peruano, para el cual estas jovencitas fantasmáticas, de anatomía rota y dislocada, y perturbadoramente sonrientes, lucen como evocaciones de aquellas cuyas vidas han sido brutalmente cegadas.

Vinculando la técnica antiquísima del cut out y el contemporáneo medio instalativo Tania Bedriñana nos recuerda la esencia ritualista del arte y la inagotable capacidad de significar de la efigie humana. 